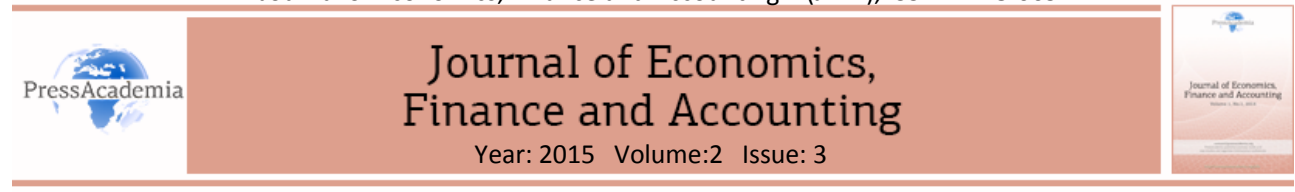

\title{
BUSINESS GROUP AFFILIATION AND FINANCIAL CONSTRAINTS: INVESTMENT-CASH FLOW SENSITIVITY OF TURKISH BUSINESS GROUPS
}

\section{DOI: 10.17261/Pressacademia.2015312958}

\section{Emin Huseyin Cetenak', Gamze Vural ${ }^{2}$}

${ }^{1}$ Nevsehir University. cetenak@gmail.com

${ }^{2}$ Cukurova University. gvural@cu.edu.tr

\section{Keywords}

Investments, cash flows, financing constraints, business groups, Turkey.

JEL Classification

G14, G31, G32

\section{ABSTRACT}

In the imperfect capital markets, the cost of external funds is greater than the cost of internal funds because of asymmetric information problems. Therefore, in these markets investment behavior largely depends on the ability of the firms' internal funds generation. This excess cost and unavailability of external funds indicate financial constraints. Investments of the firms with financial constraints depend on availability of internal funds. In this context, in the literature the investment-cash flow sensitivity of a company also signalize the degree of the company's financial constraints. In this paper, we examine investment-cash flow sensitivity of the Borsa Istanbul manufacturing firms by considering affiliation with business groups. We divide our sample into four subsamples. We find insignificant investment-cash flow relationship for the firms affiliated with a major business groups and firms which have more than \%15 foreign shareholders. On the other hand we find strong investmentcash flow sensitivity for the small business groups affiliated firms and non-affiliated independent firms.

\section{işLETME GRUBU ILIŞKISI VE FINANSAL KISITLAR: TÜRK IŞLETME GRUPLARININ YATIRIM-NAKIT AKIŞ DUYARLILIĞI ÜZERINE BIR ARAŞTIRMA}

Anahtar Kelimeler

Yatırım, nakit akışları, finansal kısıtlar, işletme grupları, Türkiye

JEL Sınıflandırması G14, G31, G32

\section{ÖZET}

Mükemmel olmayan sermaye piyasalarında asimetrik bilgi problemi nedeniyle, dışsal fonların maliyeti içsel fonların maliyetinden daha fazladır. Bu nedenle bu piyasalarda yatırımların gerçekleştirilebilmesi büyük oranda firmaların içsel fon yaratabilme yeteneğine bağlıdır. Dışsal fonların maliyetinin daha fazla olması ve istenildiği zaman erişilebilir olmaması finansal kısıtların varlığını işaret eder. Finansal kısıtı olan firmaların yatırımları daha çok içsel fonların elde edilebilirliğine, diğer bir ifadeyle firmanın nakit akışı yaratma gücüne bağlıdır. Bu bağlamda literatürde bir firmanın yatıımlarının nakit akışlarına duyarlıığı aynı zamanda o firmanın finansal kısıt derecesine de işaret etmektedir. Bu çalışmada Borsa İstanbul'da işlem gören sanayi işletmeleri için yatırımların nakit akış duyarlılığı işletme grupları özelinde test edilmiştir. Dört gruba ayrılan örneklemde büyük işletme gruplarına bağı şirketler ile yabancı ortaklık payı \%15'i aşan şirketlerin yatırımlarının nakit akışlarına duyarlı olmadığı tespit edilmiştir. Diğer taraftan küçük bir işletme grubuna bağlı olan şirketler ile her hangi bir gruba bağlı olmayan bağımsız şirketlerin yatırımları ile nakit akışları arasında anlamlı pozitif bir ilişki olduğu tespit edilmiştir. 


\section{GiRiş}

Ülke ekonomileri için sadece firmaların yatırım davranışı değil aynı zamanda bu yatırımların uygun şekilde finansmanı da son derece önemlidir. Çünkü finansal piyasalarda yaşanan sürtünmeler (Financial Frictions) yatırımların zamanında ve uygun koşullarda yapılamamasına ve bunun sonucunda da ekonomik büyümenin yavaşlamasına neden olur (Islam ve Mozumdar, 2007). Bu nedenle finans ve ekonomi literatüründe firmaların yatırım ve finansman davranışlarını inceleyen çok fazla çalışma mevcuttur. Bu çalışmaların büyük bir bölümü ya teoriye uygun olarak yatırım davranışını en iyi açıklayan modeli belirlemek ya da çeşitli kamu politikalarının yatırımlar üzerindeki etkisini incelemek amacıyla yapılmıştır.

Genel olarak firmaların yatırım karalarını etkileyen çeşitli finansal faktörlerin belirlenmesi amacıyla yapılan bu ampirik çalışmaların, Modigliani ve Miller'in (1958) yatırım ve finansman kararlarının kusursuz piyasa koşullarında ilintisiz olduğunu öne süren öncül çalışmalarından etkilendiği söylenebilir. Modigliani ve Miller (1958)'e göre mükemmel sermaye piyasalarında, dışsal fonlar içsel fonları tam olarak ikame edeceğinden, finansman tercihi, yatırımlarla ilintisiz olacaktır (Fazzari, Hubbard ve Petersen, 1988, s.141). Ancak sermaye piyasalarının kusursuz olmaması nedeniyle bu alanda yapılan çalışmalarda Modigliani ve Miller (1 958) 'in görüşlerini destekleyen ampirik bulgulara ulaşılamamıştır. Daha sonra Myers ve Majluf'un (1984) öncülük ettiği, asimetrik bilgi problemi ve kusurlu sermaye piyasaları ile ilgili çalışmalarda, asimetrik bilgi probleminin içsel ve dışsal finansman tercihini etkilediği, kusurlu piyasalarda dışsal finansmanın içsel finansmandan daha maliyetli olduğu sonucuna ulaşılmıştır.

Nakit akışlarının firmanın yatırım harcamaları üzerindeki etkisinin açıklanmasında da sermaye piyasalarının kusurlu olması olgusu önemli bir çıkış noktası olmaktadır. Kusurlu sermaye piyasalarında ortaya çıkan asimetrik bilgi problemi, fon arz edenlerin, fon talep edenlerin yatırım fırsatlarının kalitesini tam olarak değerleyememesine neden olur. Bu da, fon talep edenlerin sermaye piyasalarına erişiminde eşitsizlik yaratır ve dışsal fonların daha maliyetli hale gelmesine neden olur. Sonuç olarak, yeni borç veya hisse senedi ihracı ile sağlanacak fonların maliyeti, nakit akışları ve alıkonulan karlar yoluyla yaratılan içsel fonların fırsat maliyetinden önemli derecede farklılaşabilmektedir. Bu maliyet dezavantajının düşük düzeyde olduğu durumlarda firmaların yatırımları sadece alıkonulan karlarla değil, dışsal fonlarla da finanse edilebilir. Böyle bir durumda firmalar yatırımlarını kesintiye uğramadan sürdürülebilir. Ancak maliyet dezavantajının önemli düzeylerde olduğu durumlarda firmalar düşük maliyeti nedeniyle kazançlarının çoğunu alıkoyarak yatırımlarına yönlendirirler. Bu da yatırımların, nakit akışlarındaki dalgalanmalara bağlı olarak hareket edeceği anlamına gelmektedir (Fazzari vd.,1988,s.142). Cleary ve diğerleri (2007) daha yüksek düzeyde asimetrik bilgi problemi ile karşılaşan firmaların yatırım-nakit akış duyarlılığının daha yüksek olduğunu göstermiştir. Ağca ve Mozumdar (2008) sermaye piyasa aksaklıklarının azalmasıyla, içsel ve dışsal fonların maliyetleri arasındaki farkının azaldığını böylece yatırım-nakit akışı duyarlıı̆̆ının da düştüğünü belirtmektedirler.

Finansal kısıtların veya bilgi asimetrisinin olmadığı mükemmel piyasalarda bir firmanın nakit akışları ile yatırımları arasında doğrusal bir ilişki olmaması beklenir. Diğer taraftan kusurlu piyasalarda içsel fonlarla dışsal fonların maliyeti arasında bir fark söz konusu 
olacağından, bu piyasalarda yatırımların gerçekleştirilebilmesi; başta içsel fon yaratabilme yeteneğine daha sonra yeni özsermaye ihracı imkanına veya kredi piyasalarının işlevselliğine bağlı olacaktır. Fazzari vd. (1988), Myers ve Majluf (1984)'un finansman hiyerarşisi teorisi bağlamında içsel fonların yatırım harcamaları üzerindeki etkisinin pozitif olmasını, bir başka ifade ile yatırım harcamaları ile nakit akışlarının arasında doğrusal bir ilişki olmasını, firmanın finansal kısıta sahip olduğu şeklinde yorumlamıştır. Borçlanma veya yeni özsermaye ihracı imkanının, yani dışsal finansmanın, içsel fonlarla finansmana göre daha maliyetli olması ve/veya bu fonların istenildiği zaman ulaşılabilir olmamasını ifade eden finansal kısıtlar, firmaların net bugünkü değeri pozitif olan yatırım projelerinden vazgeçmesine bir başka ifadeyle düşük yatırım (underinvestment) problemine neden olurlar. Dolayısıyla finansal kısıta sahip firmaların yatırımları daha çok içsel fonların elde edilebilirliğine, bir başka deyişle firmanın nakit akışı yaratma gücüne bağı olmaktadır. Bu bağlamda bir firmanın yatırımlarının nakit akışlarına duyarlıı̆̆ı aynı zamanda o firmanın finansal kısıt derecesine de işaret edebilir(Fazzari vd., 1988).

Finansal kısıtların, firmaların yatırım davranışı üzerine etkileri konusundaki literatür oldukça geniştir. Bu konudaki ilk çalışmada Fazzari vd. (1988) karpayı ödeme oranı düşük olan firmaları finansal kısıtı daha yüksek firmalar, karpayı ödeme oranı yüksek olan firmaları finansal kısıtı daha az olan firmalar ön kabulü ile gruplandırmıştır. Finansal kısıtı yüksek olan firmaların yatırımlarının, nakit akışlarına daha duyarlı olduğu ve bu firmaların karlarının hemen hemen tamamını alıkoyduğunu saptamıştır. Yatıııların nakit akışlarına duyarlılığını inceleyen sonraki bir çok çalışmada, bu duyarlılığın, firmaların finansal kısıtının belirleyicisi olup olmadığı incelemiştir. Bu çalışmalarda çoğunlukla yatırım-nakit akışı duyarlılığı yüksek olan firmaların daha fazla finansal kısıta sahip olduğu sonucuna ulaşılmıştır (Chrinko ve Schaller, 1995; Hubbard, Kashyap ve Whited,1995; Hubbard, 1998). Daha sonra yapılan çok ülkeli çalışmalarda da nakit akışları ile yatırımlar arasında güçlü anlamlı ilişkiler saptanmıştır (Kadapakkam vd.1998, Aggarwal ve Zong 2006, Clearly vd., 2007, Leaven, 2003).

Bu yaklaşıma karşı çıkan çalışmalar öncelikle finansal kısıtı olan ve olmayan firma ayrımının doğru bir şekilde yapılıp yapılmadığını tartışmaktadır. Kaplan ve Zingales $(1997,2000)$ finansal raporlara dayalı, daha ayrıntılı bilgilerden faydalanarak firmaları "finansal kısıtı olan", "finansal kısıtı muhtemel olan" ve "finansal kısıtı olmayan" firmalar olarak ayırmış ve daha az finansal kısıtı olan ABD firmalarının yatırımlarının nakit akışlarına duyarlılığının daha yüksek düzeyde olduğunu belirlemiştir. Cleary (1999) de çalışmasında aynı bulgulara ulaşmıştır. Teoriyle çelişen bu sonuçlar, finansal kısıtı olan ve olmayan firmaların ayrımında kullanılacak uygun faktörlerin belirlenmesinin önemini ortaya çıkarmaktadır (Moyen,2004; Cleary ve diğerleri 2007). Mizen ve Vermeulen (2005) bu konuda finansal sıkıntı içindeki firmalar için nakit akış duyarlılığının azalabileceğini, böylece finansal kısıtı olan firmalar için literatürde yer alan bu alışılagelmiş ilişkinin tersine dönebileceğini vurgulamaktadır. Gomes (2001) çalışmasında, finansal kısıtın belirlenmesinde yatırım-nakit akış duyarlılığının teorik olarak ne gerekli ne de yeterli olduğunu belirtmektedir. Chen ve Chen (2012) Compustat FTP yıllık verilerini kullanarak 1967-2006 dönemi için imalat firmaları üzerinde yaptıkları çalışmalarında, yatırım nakit akış duyarlılığının zayıfladığını ve son dönemlerde hatta 2007-2009 kriz döneminde ortadan kalktığını belirlemişlerdir. Finansal kısıtın tamamen ortadan kalkmadığı düşünüldüğünde ise yatırım nakit akış duyarlılığının, 
finansal kısıtın belirlenmesinde iyi bir ölçüt olmadığını da vurgulamışlardır. Yatırımların nakit akışlarına duyarlılığının kaybolmasını açıklamaya Tobin Q ile ilgili ölçüm hatalarının yardımcı olduğu ve nakit akışlarının yatırım fırsatları ile ilgili olarak içerdiği bilginin zaman içinde azaldığı belirtilmektedir.

Ülkeler arasında karşılaştırma yapmayı mümkün kılan uluslararası çalışmalarda, firmaların yatırım nakit akışlarına duyarlılık derecelerindeki farklılıkların nedeni de açıklanmaya çalışılmaktadır. Bu çalışmalarda, firmanın faaliyet gösterdiği ülkenin finansal sisteminin özellikleri (banka ya da sermaye piyasası temelli olması, gelişmişlik düzeyi vb.) finansal kısıtı etkileyen dışsal bir faktör olarak ele alınmakta ve finansal kısıtı olan ve olmayan firmaların ayrımında kriter olarak kullanılmaktadır (Bond ve diğerleri 2003; Aggarwal ve Zong, 2006).

Öte yandan literatürde bazı çalışmalar yatırım-nakit akışı duyarlığını vekalet maliyetleri çerçevesinde incelemektedir. Lin vd.( 2011) 1994-2002 dönemi ABD şirketleri üzerinde yaptıkları çalışmada, kontrol hakları ile nakit akış hakları arasındaki ayrışmanın, dışsal finansman kısıtı üzerinde etkili olduğunu göstermiştir. Çalışmaya göre bu etki, küçük ölçekli, kredi derece notu veya borsaya kaydı olmayan firmalar gibi bilgisel şeffaflığı daha az olan firmalar için daha çarpıcı olmaktadır. Wei ve Zhang (2008), Asya krizi öncesi dönemini ele alarak, Doğu Asya gelişen piyasaları üzerine yaptıkları çalışmada, en büyük ortağın nakit akış hakları arttığında, yatırımların nakit akışlarına duyarlılığının azaldığını, bu duyarlılığın, firmanın en büyük ortağının nakit akış hakları ile kontrol hakları arasındaki ayrışma derecesi yükseldiğinde ise arttığını saptamışlardır. Bu sonucu serbest nakit akışı hipotezi ile tutarlı olarak yorumlayan araştırmacılar, yöneticinin kontrolündeki serbest nakit akışının artmasının, aşırı yatırımı beraberinde getirdiğini ve bu durumun özellikle serbest nakit akışları ile kontrol haklarının oldukça fazla ayrıştığı ve karlılığın daha düşük olduğu firmalar için doğru olduğunu vurgulamışlardır.

Bond ve diğerleri (2003), Avrupa ülkeleri arasında yatııım-nakit akışı duyarlılığını karşılaştırdıkları çalışmalarında, İngiltere'deki firmaların yatırımlarının nakit akışlarındaki dalgalanmalara, diğer Avrupa ülkelerindeki firmalardan daha fazla duyarlı olduklarını saptamışlardır. Mizen ve Vermeulen (2005) çalışmasında, yatırım-nakit akışı duyarlılı̆̆ının İngiltere'de Almanya'dan daha yüksek olmasının nedenleri araştırılmıştır. Bu duyarlılık farklılığının, ülkenin finansal sisteminin piyasa odaklı veya banka odaklı olmasına ve öte yandan firma ölçeği, sermaye yoğunluğu, borçlanma kapasitesi, dışa açıklık gibi firmaya veya sektöre özgü belirli karakteristiklere bağlı olabileceği öne sürülmüş ve bunların etkileri araştırılmıştır.

Literatürde, firmanın bir işletme grubuna dahil olup olmaması da firmanın finansal kısıt durumunu etkileyecek diğer önemli bir dışsal faktör olarak ele alınmaktadır. Birbirlerine formal (resmi) veya informal (gayri resmi) ilişkiler yoluyla bağlanmış firmalar takımı olarak tanımlanan işletme grupları, bağı firmalarına, bağımsız bir firmaya göre dış finansman kaynaklarına daha kolay erişim imkanları sunmakta ayrıca grup firmaları için grup içi finansman desteği de söz konusu olabilmektedir. İşletme grupları bazı durumlarda bünyesinde içsel bir sermaye piyasası yaratabilmekte, bu sayede bağlı şirketlerine daha kolay ve düşük maliyetle fonlar sunarak piyasa aksaklıklarının üstesinden gelebilmektedir. Litaratürde bir çok çalışmada bir gruba bağlı olmanın finansal kısıtı önlediği, bağımsız 
firmaların ise yatırımlarını içsel fonlar aracılığıyla gerçekleştirdiği sonucuna ulaşıımıştır (Deeloof, 1998).

Çalışmanın bundan sonraki bölümünde işletme grupları açısından nakit akış duyarlılığı ele alınacak, üçüncü bölümde ise bir işletme grubuna bağlı olmanın finansal kısıtı azaltmada etkili olup olmadığı Türkiye için ampirik olarak araştırılacaktır.

\section{LITERATÜR}

Dünyada gelişmiş ve gelişmekte olan birçok ekonomide örnekleri görülebilen işletme gruplarının varoluş nedenlerinin ve gelişim süreçlerinin, bulundukları ülkenin ekonomik, tarihi, sosyal, politik ve piyasa koşullarına bağlı olarak açıklanabileceği söylenebilir. Finans teorisi açısından bakıldığında işletme grupları, piyasa aksaklıklarına bir cevap olarak ortaya çıkmıştır (Caves, 1982). Bu nedenle sermaye piyasalarının, yatırım projelerinin finansmanını sağlayacak kadar etkin olmaması durumunda, işletme gruplarının söz konusu piyasaları ikame edecek şekilde hareket etmeleri beklenir. İ̧̧letme gruplarının oluşturduğu içsel sermaye piyasası, firma ile dışsal sermaye piyasaları arasında yer almaktadır (Çetenak, 2012).

Sahip olduğu şirketlerden elde ettiği fonları bir havuzda toplayarak kendi sermaye pazarını oluşturan işletme grupları, bu sayede piyasa aksaklıkların üstesinden gelerek söz konusu piyasada ciddi rekabet avantajı elde etmiş olmaktadır. Finansal etkinliği destekleyen bu yapı sayesinde işletmeler intiyaç duydukları finansal kaynağı dışarıya göre daha az maliyetle elde etme şansına sahip olmaktadırlar (Hill, 1988). Williamson (2008) bu görüşü işlem maliyeti yaklaşımı perspektifi ile desteklemektedir. Grup içi finansmanda, şirketin finansal yapısı ile ilgili yeterli bilgiye sahip olan kredi verenler, bu fonların gruba bağlı firmalara sadece düşük maliyetle değil ayrıca hızlı ve zamanında ulaşmasını da sağlamaktadır. Bu açıdan da grup şirketleri için bir rekabet avantajı yaratılabilmektedir (Knoll, 2008:43).

İşletme grubu üyeliği bağlı firmaların dışsal finansmanını temelde iki nedenden dolayı kolaylaştırmaktadır. Bunlardan birincisi, bankaların ve diğer finansal kurumların grup üyesi firmalara kredi vermede daha istekli olmaları, ikincisi grubun genel merkezinin, üyelerinin dışsal sermaye piyasalarına girişini desteklemesidir. Dışsal finansmanı kolaylaştıran bu etkenler işletme gruplarının yapısından kaynaklanan bazı avantajlar nedeniyle söz konusu olmaktadır. İşletme grubu üyeleri arasındaki çapraz özsermaye sahipliği, firmalar arası verilen/alınan krediler, müşterek borç garantileri şeklindeki finansal bağıılık grup içerisinde ahlaki risk problemini en aza indirmeye katkıda bulunmaktadır. Ayrıca işletme gruplarının çeşitlendirilmiş yapısı risk paylaşımının etkin bir aracı olabilmektedir. Asimetrik bilgi problemi nedeniyle kusurlu hale gelen piyasalarda grup üyeliği, ters seçimin etkilerini azaltmakta, istikrarlı nakit akışları gibi nedenler de grup firmalarına güveni arttırmaktadır. Yine borç garantileri, grup şirketleri için finansal sıkıntı olasılığını düşürebilmektedir. Ayrıca işletme grubunun piyasadaki itibarı, yüksek kalitede bir marka gibi algılanması kreditörleri grup içindeki firmalara kredi vermede daha istekli hale getirmektedir. Özetle grup firmaları yasal olarak ayrı kuruluşlar olsa da, grup firmaları güçlü bir ağ yapısı içinde olduklarından, şirketler arası krediler, birikim ve yatırımlarla birbirlerini desteklemektedirler (Lensink vd., 2003). İşletme grupları bağlı firmalarını desteklerken, kimi zaman banka gibi davranmakta, 
kimi zaman da başka şirketlere ortak olma yoluyla bir hisse senedi piyasası ya da risk sermayesi şirketi gibi davranmaktadırlar. İşletme gruplarında risk grup üyeleri tarafından paylaşılmaktadır (Khanna ve Yahef, 2005).

Sonuç olarak işletme grupları, bir taraftan grup üyeleri için dışsal finansmana ikame olabilecek içsel bir sermaye piyasası oluşturmakta, diğer taraftan da dışsal sermaye piyasasından finansmanı üyeleri için daha kolay ve uygun hale getirmektedir. Böylece işletme grupları asimetrik bilgiye dayalı piyasa aksaklıklarının aşılmasında ve işlem maliyetlerinin azaltılmasında önemli bir rol oynamaktadır. Buradan hareketle yatırım-nakit akışı duyarlılı̆ı ya da finansal kısıtlar bağlamında işletme grubuna dahil firmalarla bağımsız firmaların yatırım-nakit akış duyarlılığının farklı olması beklenmektedir. Kusursuz piyasalarda olması gerektiği gibi grup firmalarının yatırım nakit akış duyarlılığının görece az olması veya hiç olmaması, bu firmalar için yatırım kararlarında asıl belirleyicinin yatırım fırsatlarının değerinin olduğu anlamına gelmektedir. Dolayısıyla işletme grubu yapısı fonların etkin tahsisine de önemli rol oynamaktadır.

Ancak yukarıda sayılan yararlar dışında grup yapısının bağlı şirketler üzerinde çeşitli olumsuz etkileri de olabilir. Örneğin grubun hakim ortak ve/veya yöneticileri kendi çıkarlarını artırmak adına diğer paydaşların çıkarlarını göz ardı edebilir. Bu da beraberinde bazı vekalet maliyetlerini ve problemlerini getirir. Grubun hakim ortakları, kişisel amaçları doğrultusunda bazı grup şirketlerini grup içerisindeki kaynak aktarım mekanizması aracılığıyla daha az karlı ya da daha riskli duruma getirebilir. Ya da grup şirketlerinde bürokrasi ve diğer yönetim zorlukları şirketlerin performansını olumsuz etkileyebilir. Benzer şekilde, özellikle gelişmiş ülkelerdeki sermaye piyasalarının olumsuz grup algısı bazı durumlarda grup şirketlerinin bu piyasalardan yararlanma olanaklarını etkileyebilir. Bunun dışında grubun üstlendiği sigorta rolü, özellikle başarılı grup şirketleri için bir maliyet unsuru olmaktadır. Çünkü söz konusu sistemde zayıf şirketler, varlıklarını sürdürebilmek için daha güçlü şirketlerden yapılan transferler/işlemler aracılığıyla desteklenirler. Bu durumda gruba bağlı olmanın güçlü şirket için bir maliyeti, zayıf şirket için ise yararı söz konusudur (Çetenak, 2012).

Grup firmaların yatırım nakit akış duyarlılığına ilişkin literatürün geniş bir alana yayıldığı görülmekte ama temelde birer içsel sermeye piyasası olan grup firmalarında beklendiği gibi nakit akış duyarlıı̆ı̆ının bağımsız firmalara göre daha az olup olmadığı test edilmektedir. Analizlere işletme grubunun bulunduğu ekonominin gelişmiş veya gelişmekte olan bir ekonomi olup olmadığı veya finansal sisteminin yapısı ve gelişmişlik düzeyi gibi dışsal faktörler ve firmaların yaşı, büyüklüğü, ortaklık yapısı gibi içsel faktörler dahil edilerek, çalışmalar derinleştirilmektedir. Ayrıca ar\&ge yatırımları, riskinin ve belirsizliğinin daha yüksek olması, daha fazla enformasyon problemi içermesi ve değerlemesinin zor olması yönüyle diğer sermaye yatırımlarından ayrı tutularak, bu yatırımların içsel fonlarla finanse edilmesi yönündeki eğiliminin yüksek olduğu görüşünden yola çıkılarak, literatürde ar\&ge yatırımlarının nakit akışlarına daha fazla duyarlı olup olmadığının tespitine yönelik çalışmalar da göze çarpmaktadır.

Islam ve Mozumdar (2002)'ın , 31 ülke üzerinde yaptıkları çalışmada finansal piyasaların gelişimi ile içsel sermaye piyasalarının (grup içi finansman) önemi arasında negatif ilişki olduğu saptanmıştır. Ayrıca daha küçük firmaların grup içi fonlara daha bağımlı oldukları 
belirtilmektedir. Gelişmekte olan ülkelerin çoğunda işletme gruplarının büyük bir bölümünün özellikle bünyelerinde bulunan bir banka aracılığıyla kendi içsel sermaye piyasalarını yaratarak, gelişmemiş sermaye piyasalarını ikame etmesinin mümkün olabildiği görülmektedir(Hoshi vd.1991; Lincoln vd. 1996; Lincoln ve Gerlach, 2004).

Shin ve Park (1999) Kore'de 629 firma üzerinde yaptıkları çalışmada işletme grubuna dahil firmalarla bağımsız firmaların yatıım-nakit akış duyarlılığını karşılaştırmışlar ve grup firmalarının yatırımlarının nakit akış duyarlılığının daha az olduğunu saptamışlardır. Çalışmada, grup firmalarının yatırımlarının önemli derecede büyüme fırsatları ile ilgili olduğu, bu durumun holding firması olmayanlar için geçerli olmadığı, holding firmalarının yatırımlarının holding içindeki diğer firmaların nakit akışlarından etkilendiği(ayrıca bkz.Shin ve Stulz,1998), holding firmalarının yaratmış oldukları içsel sermaye piyasası ile finansal kısıtlarının azaldığı belirtilmektedir. Grup firmalarıyla karşılaştırıldığında, bağımsız firmaların, finansal kısıtının grup firmalarından daha fazla olduğu, bu firmaların düşük kaldıraç düzeylerine ve iyi yatırım fırsatlarına rağmen, proje finansmanlarının nakit akış yaratma gücüne daha fazla bağlı olduğu saptanmıştır.

Bu konudaki bazı ampirik çalışmalar ise, teorik olarak grubun temel değer kaynağı olduğu ileri sürülen içsel sermaye piyasalarının, kaynakların etkinsiz tahsisine ve dolayısıyla değer kaybına neden olan bir unsur da olabildiğine de dikkat çekmektedir. Kaynaklar ve yatırım fırsatlarının çeşitliliği arttığında, fonlar etkin yatııımlar yapamayan daha az değerli birimlere aktarılabilmektedir (Rajan ve diğerleri, 2000). İçsel sermaye piyasasındaki fonların etkin olarak dağıtılmasını engelleyen faktörlerin ortaya çıkmasıyla, grup bünyesinde kar etmeyen işletmelerin varlığının sürmesi, bazı karlı yatırım projelerinin de hayata geçirilmemesi söz konusu olabilmektedir. Yatırımların nakit akışlarına duyarlığı açısından bakıldığında, grup içindeki bir firmanın, diğer firmaların nakit akışlarına duyarlılığı, o firmanın yatırım fırsatlarının diğerlerinden daha iyi olup olmadığına bağlı olmayabilmekte ve grup içinde iyi yatırım fırsatları olan firmalarla, diğerlerinin nakit akış duyarlılığı aynı olabilmektedir (Shin ve Stulz, 1998).

Hoshi ve diğerleri (1991) sermaye piyasalarındaki enformasyon probleminin hem finansal yapı hem de yatırımlar üzerinde önemli etkileri olduğunu belirtmekte, sermaye piyasalarında enformasyon problemi olduğunda, içsel fonların elde edilebilirliğinin dolayısıyla likiditenin yatırımlar üzerinde önemli bir belirleyici olduğuna ve finansal aracı olarak bankaların enformasyon problemini azaltmadaki rolüne dikkat çekmektedir. Japon imalat firmaları üzerinde yaptıkları bu çalışmada, bankalar ile bağlantısı daha zayıf olan, sermaye artışında daha büyük problem yaşayan bağımsız firmaların yatırımlarının nakde duyarlılığının, büyük bankalarla ilişkisi güçlü, dışsal finansman kaynağı olarak krediye ulaşmada daha avantajlı olan endüstriyel grup firmalarınkinden daha yüksek olduğunu saptamışlardır. Kato ve diğerleri (2002) Japon firmaları üzerine yaptıkları çalışmalarında bağımsız firmaların (nonkeiretsu firm) yatırım harcamalarının likidite kısıtına duyarlılığının, holding firmalarından (keiretsu firm) daha yüksek olduğunu saptamıştır.

He vd.(2013)'nin Çin'deki işletme grupları üzerinde yaptıkları çalışmada, işletme gruplarının gelişen piyasalarda az gelişmiş ekonomik kurumları telafi etmedeki rolü üzerinde durulmuş, az gelişmiş finansal piyasalar, zayıf bir yasal sistem ve yüksek devlet müdahale düzeyi ile karakterize edilen bir çevrede, içsel sermeye piyasası oluşturup 
oluşturamadıkları araştırılmıştır. İşletme gruplarının, üyelerine finansal kısıtı aşmada yardımcı oldukları saptanmıştır. Zayıf bir kurumsal çevrede, işletme grupları üyelerine daha fazla finansal serbestlik sağlayabilse de, bu serbestliğin derecesinin, ülkedeki zayıf yapıyla sınırlandığı, bu nedenle, gelişmiş kurumların içsel sermaye piyasalarının faaliyet etkinliği için gerekli olduğu belirtilmiştir.

Kadapakkam, Kumar, Leigh ve Riddick (1998), OECD ülkelerinden Kanada, Fransa, Almanya, İngiltere, Japonya ve Amerika üzerinde 1982-1991 verileri ile yaptıkları çalışmalarında nakit akışlarının firma yatırımları üzerindeki etkisini incelemiştir. Firma ölçeğindeki farklılığı dikkate almaksızın bu altı ülkede firma yatırımlarının içsel kaynaklardan etkilendiği sonucuna ulaşmışlardır. Yatırım düzeyi ile içsel fonların elde edilebilirliği arasında anlamlı ilişkinin olduğunu ayrıca yatırım düzeyi ile Tobin $Q$ arasında da pozitif ilişkinin varlı̆̆ını belirlemişlerdir. Firma ölçeği dikkate alındığında ise yatırım nakit akış duyarlılığının büyük firma ölçeğindeki grupta en yüksek, küçük firma ölçeği grubunda ise en düşük olduğunu saptamışlardır. Firmanın yatıımlarının nakit akışlarına duyarlılık derecesinin, o firmanın sermaye piyasalarına girişinin diğer bir deyişle finansal kısıtının doğru bir ölçüsü olamayacağını belirtmişlerdir.

Beck vd. (2006) 80 ülkede 10.000 firma üzerine yaptıkları çalışmalarında finansal kısıtı olan ve olmayan firmaların ayrımını yapmaya ve finansal kısıtın belirleyicilerinin neler olduğunu saptamaya çalışmışlardır. Çalışmada firmanın yaşı, ölçeği, bulunduğu sektör, sahiplik yapısı (kamu sahipliğinde olması, yabancı sermayeli olması), çok uluslu firma özelliğinde olması, borsada işlem görmesi veya işletme grubuna dahil olması gibi firma özellikleri dikkate alınmıştır. Yaş, ölçek ve sahiplik yapısının finansal kısıtın en iyi belirleyicileri olduğu ve daha genç, daha küçük ve yerel firmalarının finansal engelinin daha fazla, daha eski, daha büyük ve yabancı sermaye sahipliğinin olduğu firmaların ise finansal kısıtının daha az olduğu saptanmıştır. Holding firmalarının finansal kısıtının daha az olduğuna ilişkin bir bulguya ulaşamamışlardır. Ayrıca firmanın bulunduğu ülkenin karakteristiği dikkate alındığında finansal aracılık gelişim düzeyi daha yüksek, borsası daha likit, daha etkin bir yasal sistemi olan ve kişi başına GSYH'nın daha yüksek olduğu ülkelerdeki firmalarda finansal kısıtının daha düşük olduğu belirlenmiştir.

Khanna ve Palepu (2000) Hindistan işletme grupları ile bağımsız firmaların performanslarını karşılaştırdıkları çalışmalarında genel olarak nakit akışı-yatırım duyarlılığının yüksek olduğunu fakat işletme grubuna dahil firmalarla bağımsız firmaların nakit akış duyarlılığı arasında önemli bir farklılık olmadığını gözlemlemişlerdir. Grup firmalarının, bağımsız firmalara göre uluslararası sermaye piyasalarına daha fazla erişebildiklerini belirtmişlerdir. Yine Hindistan işletme grupları üzerine George, Kabir ve Qian (2011) tarafından yapılan çalışmada da, hem grup şirketlerinde hem de bağımsız firmalarda yatırım nakit akış duyarlılığının yüksek olduğu, grup şirketleri ile bağımsız şirketlerin duyarlııkları arasında ise anlamlı bir farklılık bulunmadığı yönünde bulgular ulaşılmıştır. Yatırım-nakit akışı duyarlılığının finansal kısıtı gösteren güvenilir bir ölçüt olup olmadığı da belirlenmeye çalışıımış, araştırmacıların firmanın yatırım-nakit akış duyarlıı̆̆ı ile finansal kısıt durumunu doğrudan ilişkilendiremeyeceği vurgulanmıştır.

Sasidharan vd.(2015) ise Hindistandaki imalat firmaları üzerinde yaptıkları çalışmada finansal kısıt ile ar\&ge yatırımları arasındaki ilişkiyi incelemişlerdir. Çalışmada ar\&ge 
yatırımlarının doğası gereği riskinin ve belirsizliğinin yüksek olmasının ve bu yatırımlarda genellikle birlikte yüklenimin söz konusu olmamasının bu tür projelerin finansmanında engel teşkil ettiği, sermaye yatırımlarına göre, içsel fonların ar\&ge yatırımları için daha belirleyici olduğu belirtilmiştir. Çalışmada ar\&ge yatırım harcamaları ile içsel nakit akışları arasında anlamlı pozitif ilişki saptanmış, küçük ve daha yeni şirketler için nakit akış duyarlılığının daha fazla olduğu bulgusuna ulaşılmıştır. İşletme grubu içinde yer almanın finansal kısıtı azaltma açısından avantaj yarattığı yönünde anlamlı bir sonuca ulaşılamazken, yabancı sermayeli firmaların vekalet ve enformason problemlerini azaltabildiği ve finansal kısıtlarının en az düzeyde olduğu belirtilmiştir. Bhaumik v.d.(2012) 1997-2006 dönemini kapsayan çalışmasında işletme grubuna dahil olmanın kredi açısından finansal kısıtı hafiflettiği ancak bu etkinin zaman içinde azaldığı sonucuna ulaşmıştır. Choi vd.(2014), Kore imalat firmaları üzerinde 1994-2006 dönemi için yaptıkları çalışmada, gelişen ekonomilerde piyasa odaklı kurumsal değişimlerin firmaların finansal kısıtını azaltmadaki ve bu firmaların innovasyon faaliyetlerindeki etkinliğini iyileştirilmedeki etkilerini araştırmışlardır. Kurumsal gelişimin etkilerinin, Kore işletme gruplarında ve bağımsız firmalarda, farklı olduğu, kurumsal değişikliklerin ar\&ge yatırımlarındaki finansal kısıtı, bağımsız firmalarda, grup firmalarına göre daha fazla hafiflettiği saptanmıştır. kurumsal değişikliklerin, öte yandan grup firmalarında vekalet problemlerini azalttığı belirlenmiştir.

Pindado vd. (2011) Euro Alanında dokuz ülke üzerinde 1996-2006 dönemini kapsayan çalışmalarında, aile şirketlerinin sahiplik yapısını dikkate almış, aile firmalarındaki kontrol yapısının yatırım nakit akış duyarlılığı üzerindeki etkisini araştırmışlardır. Çalışmada aile kontrolündeki şirketlerin daha düşük nakit akış duyarlılığına sahip oldukları bulgusuna ulaşılmıştır. Aile şirketlerinin etkin olmayan yatırımları yapma eğilimini azaltarak, sermaye piyasalarındaki aksaklıklara bağlı olarak ortaya çıkan yatırım etkinsizliğini hafiflettikleri belirtilmiştir. Gorodnichenko vd.(2009) Alman grup şirketleri üzerine yaptıkları çalışmada, bir gruba dahil olmanın yatırım-nakit akış duyarılığını azaltıp azaltmadığı araştırılmış, yatırım duyarlılığının küçük firmalar için anlamlı derecede azaldığı saptanmıştır. Orta ve büyük ölçekli firmalar için, bir işletme grubuna ait olmanın, yatırım-nakit akış duyarlılığını azalttığı yönünde anlamlı bir bulguya ulaşılamamıştır. Bir gruba ait olmak dolayısıyla içsel sermaye piyasasından faydalanabilmenin küçük firmalar için finansal kısıtı azalttığı sonucuna ulaşılmıştır. Fakat orta ve büyük ölçekli firmalar için, içsel sermaye piyasalarının, bu firmaları kendi fonlarındaki yetersizliğe karşı sağlama almakta, sermaye piyasalarından ve/veya bankacılık piyasasından daha başarılı olmadığı vurgulanmıştır. Alman finansal sisteminin banka temelli olduğuna dikkat çekilerek, grup şirketlerinin bilgi asimetrisini azaltabildiği, kaynak tahsisindeki etkinliği arttırabildiği ancak bu etkinin sadece küçük firma sınıfı ile sınırlı olduğu ve bu bağlamda Alman bankacılık sistemindeki küçük ölçekli firmaların finansman desteğine ilişkin uygulamaların etkinliğinin değerlendirilmesi gerektiği belirtilmiştir.

Türkiyede işletme grupları 1980'li yıllardan sonra finansal serbesti ve uluslararasılaşmaya bağlı olarak daha hızlı bir gelişme göstermiştir. Özelleştirme, kurumsal yönetimdeki gelişmeler, ekonomik büyüme ile birlikte karlı yatırım fırsatlarının varlığı ve çeşitlendirme stratejisinin değer yaratmaya katkısı, devlet politikalarının Türkiye'de aile sahipliğinin ağırlıklı olduğu grup şirketlerinin gelişiminde etkili olmuştur (Çetenak, 2012). Gelişmekte 
olan bir ekonomi olarak değerlendirilen Türkiye'de, finansal sistem, sermaye piyasalarının payı artmakla birlikte -ki sermaye piyasalarında tahvil piyasası ağırlıklıdır ve dışlama etkisi söz konusudur- banka temelli bir piyasa olarak nitelendirilmektedir (Serpam, (2012). Bankacılık piyasasında ise yabancı sahipliğinin artışı göze çarpmaktadır. Bu çalışmada ise Türk işletme gruplarının içsel sermaye piyasası yaratabilmelerine ve dışsal finansmandaki avantajları kullanabilmelerine bağı olarak bağımsız firmalara göre piyasa aksaklıklarını aşmada daha başarılı olup olmadıkları, finansal kısıtlarının daha az olup olmadığı belirlenmeye çalışılacaktır. Bunun için öncelikle yatırım-nakit akış duyarlılığının anlamlı bir açıklama gücüne sahip olup olmadığı ve grup şirketlerinin duyarlılıklarının bağımsız firmalara göre daha az olup olmadığı test edilemeye çalışılacaktır. Finansal kısıt ve yatırım nakit akışı ile ilgili olarak yapılan uluslararası çalışmalarda Türkiye gelişmekte olan piyasalar içinde kısmen yer almaktadır. Bu çalışma ise yalnızca Türkiye işletme gruplarını ele almakta ve bağımsız firmalara göre finansal kısıt düzeylerini karşılaştırmada daha ayrıntılı analizler içermektedir. Bu yönüyle çalışmanın, literatürdeki Türk firmalarının finansal kısıtının belirlenmesine yönelik açı̆̆ı kapatma ve Türkiye'deki şirket yöneticileri, kreditörler, yatırımcılar ve politika yapıcılarına daha aydınlatıcı bilgiler verme konusunda önemli katkılar sunacağı düşünülmektedir.

\section{VERI SETI VE YÖNTEM}

Bu çalışmada işletme grubu ilişkisinin yatırımların finansmanında etkili olup olmadı̆̆ı, bir başka ifade ile işletme grubu ilişkisinin, finansal kısıtlar üzerindeki etkisi test edilmiştir. Bu amaçla Borsa İstanbul'da işlem gören 164 sanayi şirketinin 2004-2012 yılları arasındaki verilerinden faydalanılmıştır. Veriler Borsa İstanbul'un internet sitesinden, Kamuyu Aydınlatma Platformu'nun internet sitesinden ve Finnet veri tabanından alınmıştır. Çalışmada, dinamik panel tahmin yöntemlerinden biri olan ve son yıllarda iktisat ve finans yazınında sıklıkla kullanılan Genelleştirilmiş Momentler Metodunun sistem versiyonu kullanılmıştır.

Literatürde yatırımların nakit akışlarına duyarlılığını test etmek amacıyla en çok kullanılan modellerden biri Q Yatırım Modelidir. Bu modele göre firmaların yatırımları, öngörülen gelecek karların bir göstergesi olan piyasa değerinin bir fonksiyonudur (Brainard ve Tobin, 1968, Hayashi, 1982). Q modeline göre firmaların yatırımları, finansal kısıtlamaların ve vekâlet problemlerinin olmadığı durumda, temel olarak gelecek kar fırsatları ile ilgili beklentilerin ölçütü olan ve varlıkların piyasa değerini, yerine koyma maliyetine bölerek hesaplanan Q oranı tarafından belirlenir(Gallego ve Loayza, 2000).

Q modeli firmaların gelecek kar beklentileri temelinde maksimize edilmiş değerlerinin, firmaların piyasa değerleri ile ölçülebileceğini varsaymaktadır (Bond vd. 2004:6). Bu varsayım altında piyasa değeri, beklenen gelecek karlar ile ilgili tüm bilgileri kapsar. Hayashi (1982) mükemmel rekabetçi piyasaların ve ölçeğe göre sabit getirinin olduğu durumlarda, modele eklenen $Q$ oranı dışındaki herhangi bir değişkenin ilave bir bilgi sağlamayacağını ileri sürmüştür. Bu koşulların yerine getirilmediği durumlarda ise Tobin $Q$ oranı gelecek kar beklentileri ile ilgili tüm bilgileri yansıtmayacağından, kayıp bilgiler satış ya da nakit akışı gibi içsel fonları temsil eden ilave açıklayıcı değişkenler kullanılarak elde edilebilir (Bond vd. 2004:6). 
Literatürde $Q$ modeline içsel fon değişkeni olarak en çok nakit akışı değişkeni eklenmiştir. Ve bu sayede sermaye piyasalarının etkinliği, firmaların finansal kısıta sahip olup olmadığı veya aşırı yatırım davranışının olup olmadığı tespit edilmeye çalışılmıştır. Ağca ve Mozumdar (2008) çalışmalarında Q modelini içsel fonları da dikkate alacak şekilde aşağıdaki gibi revize etmiştir:

$$
\left(\frac{I_{i, t}}{K_{i, t-1}}\right)=\alpha+\beta_{1} Q_{i, t-1}+\beta_{2}\left(\frac{C F_{i, t}}{K_{i, t-1}}\right)+\varepsilon_{i, t}
$$

Burada I duran varlık yatırımlarını, $Q$ Tobin $Q$ oranını, $K$ sermaye stokunu, CF ise nakit akışlarını göstermektedir. Sermaye piyasalarının etkinliğini test etmek amacıyla oluşturulan bu modelde Ağca ve Mozumdar (2008) zaman içerisinde Nakit Akışı değişkeni katsayısında yaşanan gelişmeleri incelemişlerdir.

Modele ilave edilen nakit akışı değişkeninin istatistiksel olarak anlamlı olması literatürde 3 farklı şekilde yorumlanmaktadır(Egimbaeva, 2013). Birinci görüşe göre q modelindeki anlamlı nakit akışları, firmaların mükemmel olmayan sermaye piyasaları nedeniyle finansal kısıtlarla yüz yüze kaldığını göstermektedir (Gallego ve Loayza, 2000; Fazzari vd., 1988). íkinci görüşe göre anlamlı nakit akışı, piyasa değeri ile ilgili ölçüm hataları nedeniyle q oranının doğru belirlenmediğini bu nedenle q modelinin iyi çalışmadığını gösterir. Çünkü etkin olmayan sermaye piyasalarında firmaların piyasa değeri gerçeği yansıtmayacağından yanlış hesaplanan q oranı nedeniyle q modeli anlamlı sonuçlar vermeyecektir ( Erickson ve Whited, 2000; Alti, 2003). Anlamlı nakit akışının yorumlanması ile ilgili üçüncü görüş ise vekalet maliyetlerini işaret etmektedir. Bu görüşe göre ise yöneticiler içsel kaynakları olması gerekenden daha fazla yatırım yapmak için kullanmaktadır. Bu yüzden nakit akışı değişkeni ile yatırımlar arasında doğrusal bir ilişki olması beklenir (Richardson, 2006).

\section{AMPIRIK BULGULAR}

Bu çalışmada işletme grubu ilişkisinin finansal kısıtlar üzerindeki etkisini tespit etmek amacıyla, literatürde yer alan çalışmalarla da uyumlu olarak, 164 firmanın 9 yıllık verilerinden oluşan örneklem, ortaklık yapısına göre 4 alt gruba ayrılmış ve yatırımların nakit akışlarına duyarlılığı ayrı ayrı test edilmiştir. Firmanın hakim ortaklarına bağlı olarak oluşturulan 4 alt grup şu şekildedir:

1. Büyük bir işletme grubuna bağlı olarak faaliyet gösteren firmalar,

2. Küçük bir işletme grubuna bağlı olarak faaliyet gösteren firmalar,

3. Bir gruba bağlı olmayan bağımsız firmalar,

4. En az \%15 paya sahip yabancı ortağı olan firmalar.

Araştırma konusunun amacına da bağlı olarak işletme gruplarının büyük ve küçük olarak sınıflandırılmasının nedeni, finansman konusunda büyük grupların bağlı şirketlerine daha fazla avantaj yaratabilecekleri ön kabulünden kaynaklanmaktadır. Buna göre bu araştırmada, OYAK, Koç, Anadolu, Sabancı, İşbankası, Zorlu, Doğan ve Ülker gruplarına bağlı olarak faaliyet gösteren toplam 41 şirket, büyük bir işletme grubuna bağı olarak faaliyet gösteren firmalar olarak sınıflandırılmıştır. Bir işletme grubu bünyesinde olmasına 
rağmen yukarıda sıralanan gruplara bağlı olmayan diğer şirketler "küçük bir işletme grubuna bağlı olarak faaliyet gösteren firmalar" şeklinde sınıflandırılmıştır. ìki grup arasında kararsız kalınan 8 firma örneklemden çıkarılmıştır. Diğer taraftan en az \%15 paya sahip yabancı ortağı olan bazı firmalar sadece dördüncü grupta değil aynı zamanda birinci veya ikinci gruplarda da yer almaktadır. Ancak hiçbir firma aynı anda birinci, ikinci veya üçüncü grupların ikisinde yer almamaktadır.

Tüm örneklem ve dört alt grup için GMM yöntemi kullanılarak ayrı ayrı tahmin edilen regresyon denklemi şu şekildedir:

$$
\left(\frac{I_{i, t}}{K_{i, t-1}}\right)=\alpha+\beta_{1} Q_{i, t-1}+\beta_{2}\left(\frac{C F_{i, t}}{K_{i, t-1}}\right)+\beta_{3} Y A S_{i, t}+\beta_{4} B \ddot{U} Y \ddot{U} K L \ddot{U} K_{i, t}+\varepsilon_{i, t}
$$

Ağca ve Mozumdar'ın (2008) modeline ilave olarak Büyüklük ve Yaş kontrol değişkenleri eklenerek oluşturulan modelde kullanılan değişkenlerin tanımları aşağıdaki tabloda verilmiştir.

Tablo 1: Çalışmada Kullanılan Değişkenlerin Tanımları

\begin{tabular}{ll}
\hline $\mathrm{I}_{\mathrm{t}}$ & t döneminde gerçekleştirilen yatırım harcamaları (Duran Varlık alımları ) \\
\hline $\mathrm{K}_{\mathrm{t}}$ & Sermaye Stoku (Duran Varlıklar) \\
\hline $\mathrm{CF}_{\mathrm{t}}$ & Faiz ve Vergiden Önceki Kar + Amortisman Harcamaları \\
\hline $\mathrm{Q}_{\mathrm{t}-1}$ & (Borcun Defter Değeri +Özsermayenin Piyasa Değeri) $)_{\mathrm{t}-1} /$ Toplam Aktif $\mathrm{t}-1$ \\
\hline $\mathrm{I}_{\mathrm{t}} / \mathrm{K}_{\mathrm{t}-1}$ & $\mathrm{t}$ döneminde gerçekleşen duran varlık alımları / t-1 döneminde ki Duran Varlıklar \\
\hline $\mathrm{CF}_{\mathrm{t}} / \mathrm{K}_{\mathrm{t}-1}$ & t döneminde gerçekleşen nakit akımları / t-1 döneminde ki Duran Varlıklar \\
\hline $\mathrm{YAŞt}$ & Firmanın Yaşı \\
\hline BÜYÜKLÜK & Toplam aktiflerin doğal logaritması \\
\hline
\end{tabular}

Tablo 2'de modelde kullanılan değişkenlere ait tanımlayıcı istatistiklere yer verilmiştir. Buna göre $\mathrm{t}$ döneminde yapılan yatırım harcamaların, $\mathrm{t}-1$ dönemindeki sermaye stokuna oranını gösteren $\mathrm{I}_{\mathrm{t}} / \mathrm{K}_{\mathrm{t}-1}$ oranının ortalaması tüm örneklem için 0,14 düzeyindedir. Büyük gruplara bağlı şirketlerde bu oran 0,12 , küçük gruplara bağlı şirketlerde 0,10 bağımsız şirketlerde ise 0,16 düzeyindedir. Nakit akışlarının sermaye stokuna bölünmesi ile hesaplanan $\mathrm{CF}_{\mathrm{t}} / \mathrm{K}_{\mathrm{t}-1}$ değişkeninin ortalaması tüm örneklem için 0,17 , büyük gruplara bağlı şirketler ve yabancı ortaklı şirketler için 0,23 küçük gruplara bağlı şirketler 0,09 ve bağımsız şirketler için 0,15 düzeyindedir. Bu değişkende küçük grupların düşük olan nakit akışları dikkat çekmektedir. Tobin Q oranına baktığımızda ise yine büyük gruplara bağlı şirketler ile yabancı ortaklı şirketlerin yüksek oranları dikkat çekmektedir. Diğer taraftan yaş değişkeni incelendiğinde büyük gruplara bağlı şirketlerin daha yaşlı diğer taraftan bağımsız şirketlerin ise daha genç olduğu söylenebilir. Toplam aktiflerin doğal logaritması alınarak ölçülen büyüklük değişkenine göre ise büyük gruba bağlı şirketlerin diğerlerine göre daha yüksek aktif büyüklüğüne sahip olduğu da görülmektedir. 
Tablo 2: Değişkenlere Ait Tanımlayıcı İstatistikler

\begin{tabular}{|l|c|c|c|c|c|c|c|}
\hline & \multicolumn{3}{|c|}{ TÜM ÖRNEKLEM } & Büyük Grup & $\begin{array}{c}\text { Küçük } \\
\text { Grup }\end{array}$ & Bağımsız & $\begin{array}{c}\text { Yabancı } \\
\text { Ortak }\end{array}$ \\
\hline & Ort. & Medyan & St. Sap. & Ort. & Ort. & Ort. & Ort. \\
\hline $\mathrm{I}_{\mathrm{t} / \mathrm{K}_{\mathrm{t}-1}}$ & 0,14 & 0,077 & 0,27 & 0,12 & 0,10 & 0,16 & 0,14 \\
\hline $\mathrm{CF} / \mathrm{K}_{\mathrm{t}-1}$ & 0,17 & 0,11 & 0,43 & 0,23 & 0,09 & 0,15 & 0,23 \\
\hline $\mathrm{Q}$ & 1,20 & 1,09 & 0,46 & 1,30 & 1,13 & 1,14 & 1,35 \\
\hline YAŞ & 36,47 & 37 & 13,8 & 40,63 & 36,74 & 31,44 & 38,42 \\
\hline BÜYÜKLÜK & 18,99 & 18,97 & 1,51 & 20,02 & 18,74 & 18,28 & 19,78 \\
\hline
\end{tabular}

Çalışmada kullanılan değişkenlere ait korelasyon matrisi Tablo 3'te verilmiştir. Elde edilen korelasyon katsayılarına göre değişkenler arasında dikkate değer düzeyde korelasyon ilişkisi olduğunu söylemek mümkün değildir.

Tablo 3: Korelasyon Matrisi

\begin{tabular}{|l|c|c|c|c|c|}
\hline & $\mathrm{I}_{\mathrm{t}} / \mathrm{K}_{\mathrm{t}-1}$ & $\mathbf{Q}$ & $\mathrm{CF}_{\mathrm{t}} / \mathrm{K}_{\mathrm{t}-1}$ & YAŞ & BÜYÜKLÜK \\
\hline $\mathrm{I}_{\mathrm{t}} / \mathrm{K}_{\mathrm{t}-1}$ & 1 & & & & \\
\hline $\mathrm{Q}$ & 0,04 & 1 & & & \\
\hline $\mathrm{CF}_{\mathrm{t}} / \mathrm{K}_{\mathrm{t}-1}$ & 0,30 & 0,15 & 1 & & \\
\hline $\mathrm{YAŞ}$ & $-0,15$ & 0,17 & 0,05 & 1 & \\
\hline BÜYÜKLÜK & 0,02 & $-0,10$ & 0,10 & 0,28 & 1 \\
\hline
\end{tabular}

Çalışmada Test edilen modele ait tahmin sonuçları Tablo 4'te yer almaktadır. Daha önce de belirtildiği üzere bu çalışmada Sistem GMM yöntemi kullanılarak yatırımların nakit akış duyarlılığı tespit edilmeye çalışımıştır. Yukarıda belirtilen modeli EKK yöntemi ile tahmin etmek, modelin sahip olduğu potansiyel içsellik ve heterojenlik problemleri nedeniyle yanlı sonuçlara neden olabilmektedir. Üretim teknolojisi veya yönetimsel beceriler gibi gözlemlenemeyen firma temelli etkilerden kaynaklanan heterojenlik sorunundan kaynaklanan potansiyel problemleri çözmek için, modelin birinci farkı alınarak tahmin yapılabilir. Ancak modelin birinci farkını almak ortak içselliklik sorununu (joint endogenity) çözmek için yeterli değildir(Gezici, 2009:7). Q Yatırım modelinde, bağımlı ve bağımsız değişkenler arasındaki ilişki karşılıklı olabileceğinden (yatırımların aynı zamanda $Q$ oranını yada nakit akışlarını etkileyeceğinden) modelde potansiyel olarak ortak içselliklik sorunu söz konusudur. Dolayısıyla bu iki yönlü ilişkiyi kontrol edebilmek için araç değişken yaklaşımının kullanılması gerekir(Gallego ve Loayza, 2000:25). Bu yüzden bu çalışmada açıklayıc değiş̧enlerin gecikmeli değerlerinin araç değişken olduğu GMM tahmin yöntemi kullanılmıştır. Tahmin edilen GMM modelinde yaş değişkeni katı dışsal diğer tüm açıklayıcı değişkenler ise içsel olarak kabul edilmiştir. Diğer taraftan yatırım ve finansman davranışları çeşitli makroekonomik faktörler tarafından etkilenebilir. Zaman içerisinde 
yaşanabilecek bu etkileri kontrol etmek için regresyon denklemine yıl verisi kukla değişkeni olarak eklenmiştir.

Arellano ve Bover (1995) tarafından geliştirilen sistem GMM yaklaşımında tahmincinin performansı, büyük ölçüde araç değişkenlerin geçerliliğine bağlıdır. Araç değişkenlerin geçerliliğinin test edilmesi için aşırı belirleme testi kullanılabilir. Bu doğrultuda gerçekleştirilen Hansen aşırı belirleme testi sonuçları, model tahmin sonuçlarının yer aldığı tablolarda verilmiştir. Diğer taraftan dinamik panel veri modellerinin geçerliğinin belirlenmesinde kullanılan diğer bir test de otokorelasyon (ardışık bağımlıık) testidir. Arellano ve Bond'un (1991) GM tahmincisinin tutarlılığının dayandığı en önemli varsayımlardan biri, birinci fark denkleminin hataları arasında ikinci dereceden korelasyon olmaması varsayımıdır. $\Delta u_{i t}$ ardışık bağımlı olmayan hataların birinci farkını gösterdiğinden $E \Delta u_{i t} \Delta u_{i t-1}$ in sıfır olmasına gerek yokken GMM tahmincisinin tutarlılığı bir başka ifade ile otokorelasyonun varlığı, tamamen $E \Delta u_{i t} \Delta u_{i t-2}=0$ olmasına bağlıdır (Arellano ve Bond, 1991). Bu doğrultuda gerçekleştirilen test sonuçları, model tahmin sonuçlarının yer aldığı tabloda verilmiştir.

Tablo 4 : Sistem GMM Tahmin Sonuçları

\begin{tabular}{|c|c|c|c|c|c|}
\hline & $\begin{array}{c}\text { Tüm } \\
\text { Örneklem }\end{array}$ & Büyük Grup & $\begin{array}{l}\text { Küçük } \\
\text { Grup }\end{array}$ & Bağımsız & Yabancı \\
\hline$Q_{t-1}$ & $\begin{array}{c}0,0275^{* * *} \\
(0,005)\end{array}$ & $\begin{array}{c}0,1953^{* *} \\
(0,015)\end{array}$ & $\begin{array}{l}0,0514 \\
(0,275)\end{array}$ & $\begin{array}{c}0,1274^{* *} \\
(0,050)\end{array}$ & $\begin{array}{c}0,0301^{* *} \\
(0,034)\end{array}$ \\
\hline $\mathrm{CF}_{\mathrm{t}} / \mathrm{K}_{\mathrm{t}-1}$ & $\begin{array}{c}0,1771 * * * \\
(0,001)\end{array}$ & $\begin{array}{l}0,0310 \\
(0,822)\end{array}$ & $\begin{array}{c}0,4857 * * \\
(0,011)\end{array}$ & $\begin{array}{c}0,5136 * * * \\
(0,000)\end{array}$ & $\begin{array}{l}0,0328 \\
(0,575)\end{array}$ \\
\hline YAŞ & $\begin{array}{c}-0,0067^{* * *} \\
(0,007)\end{array}$ & $\begin{array}{l}0,0110 \\
(0,631)\end{array}$ & $\begin{array}{c}0,0603^{*} \\
(0,096)\end{array}$ & $\begin{array}{c}-0,0147^{* * *} \\
(0,001)\end{array}$ & $\begin{array}{c}-0,0059 * * \\
(0,041)\end{array}$ \\
\hline BÜYÜKLÜK & $\begin{array}{c}0,0588 * * * \\
(0,000)\end{array}$ & $\begin{array}{c}0,417 * * \\
(0,047)\end{array}$ & $\begin{array}{l}-0,1652 \\
(0,505)\end{array}$ & $\begin{array}{c}0,018 \\
(0,613)\end{array}$ & $\begin{array}{l}0,052 * * \\
(0,042)\end{array}$ \\
\hline Wald Ki-Kare & $\begin{array}{c}73,02 * * * \\
(0,000)\end{array}$ & $\begin{array}{c}27,85^{* * *} \\
(0,002)\end{array}$ & $\begin{array}{c}32,14^{* * *} \\
(0,000)\end{array}$ & $\begin{array}{c}32,12 * * * \\
(0,001)\end{array}$ & $\begin{array}{c}44,56 * * * \\
(0,000)\end{array}$ \\
\hline Gözlem Sayısı & 1218 & 281 & 465 & 335 & 334 \\
\hline Grup Sayısı & 164 & 41 & 38 & 41 & 43 \\
\hline $\begin{array}{l}\text { Araç Değişken } \\
\text { Sayısı }\end{array}$ & 157 & 29 & 23 & 43 & 53 \\
\hline $\mathrm{AR}(1)$ & $\begin{array}{c}-4,01 * * * \\
(0,000)\end{array}$ & $\begin{array}{c}-2,62 * * * \\
(0,009)\end{array}$ & $\begin{array}{c}-2,67 * * * \\
(0,008)\end{array}$ & $\begin{array}{l}-2,47^{* *} \\
(0,013)\end{array}$ & $\begin{array}{l}-2,25 * * \\
(0,024)\end{array}$ \\
\hline $\operatorname{AR}(2)$ & $\begin{array}{c}-0,21 \\
(0,836)\end{array}$ & $\begin{array}{c}0,13 \\
(0,895)\end{array}$ & $\begin{array}{c}-1,21 \\
(0,226)\end{array}$ & $\begin{array}{c}0,88 \\
(0,381)\end{array}$ & $\begin{array}{c}-1,01 \\
(0,311)\end{array}$ \\
\hline $\begin{array}{l}\text { Hansen Aşırı } \\
\text { Belirleme Testi }\end{array}$ & $\begin{array}{l}151,05 \\
(0,348) \\
\end{array}$ & $\begin{array}{c}1,94 \\
(0,164)\end{array}$ & $\begin{array}{c}12,20 \\
(0,511) \\
\end{array}$ & $\begin{array}{c}27,34 \\
(0,655) \\
\end{array}$ & $\begin{array}{c}27,23 \\
(0,951) \\
\end{array}$ \\
\hline \multicolumn{6}{|c|}{$\begin{array}{l}\text { Not: 1) Parantez içerisinde yer alan değerler tahmin edilen katsayıların p değerlerini } \\
\text { göstermektedir. ***, ** ve * simgeleri katsayıların sırasıyla } \% 1, \% 5 \text { ve } \% 10 \text { önem düzeyinde } \\
\text { anlamlı olduğunu göstermektedir. 2)YIL değişkeni tabloya eklenmemiştir }\end{array}$} \\
\hline
\end{tabular}


164 firmadan oluşan tüm örneklem için elde edilen tahmin sonuçlarına göre tüm değişkenler \%1 önem düzeyinde anlamlıdır. Q oranı, nakit akışları ve büyüklük beklendiği üzere yatırımlarla pozitif yaş ise yatırımlarla negatif ilişkiye sahiptir. Buna göre firmaların yaşı artıkça yatırımları azalmakta diğer taraftan, büyüklüğü, q oranı ve içsel fonları artıkça yatırımları da artmaktadır. Nakit akışı değişkenin katsayısı 0,17 olarak tahmin edilmiştir. Büyük gruplara bağlı firmalardan oluşan alt örneklemden elde edilen tahmin sonuçlarına göre yatırım değişkeni sadece q oranı ve büyüklük değişkeni ile açıklanabilmektedir. Büyük gruba bağlı firmalar için içsel fonlar yatırımların belirleyicisi değildir. Diğer taraftan büyük olmayan bir gruba bağlı firmalar için ise durum tam tersidir. Bu firmalarda yatırımın belirleyicileri \%5 önem düzeyinde nakit akışları, \%10 önem düzeyinde ise firma yaşı değişkenleridir. Büyük olmayan bir gruba bağlı olarak faaliyet gösteren firmalar için nakit akışı değişkeninin katsayısı 0,48 olarak tahmin edilmiştir. Bağımsız şirketler için yapılan test sonuçlarına göre bu firmaların yatırım davranışları, q oranı, nakit akışları ve yaş değişkenleri kullanılarak açıklanabilmektedir. Bağımsız şirketler de, büyük olmayan bir gruba bağı şirketler gibi yatırımlarını gerçekleştirmek için içsel fonlara ihtiyaç duymaktadırlar. Diğer taraftan \%15'ten fazla paya sahip olan bir yabancı ortağın olduğu işletmeler için nakit akışı değişkeni anlamlı değildir. Elde edilen sonuçlardan hareketle, bu şirketlerin yatırımlarının belirleyicilerinin q oranı, yaş ve büyüklük olduğu söylenebilir.

\section{SONUÇ}

Bu çalışmada işletme grubu ilişkisinin yatırımların finansmanda etkili olup olmadığı, bir başka ifade ile ortaklık yapısının, finansal kısıtlar üzerindeki etkisi test edilmiştir. Bu amaç doğrultusunda Borsa İstanbul'da işlem gören 164 sanayi işletmesinin verilerinden yararlanılarak, $Q$ yatırım modeli ile işletmelerin finansal kısıta sahip olup olmadığı diğer bir deyişle işletmelerin, yatırım finansmanında içsel fonlara bağımlılı̆̆ı, test edilmiştir. Örneklemde yer alan firmaların, ortaklık yapılarına göre alt gruplara ayrılması ile elde edilen tahmin sonuçlarına göre, büyük işletme gruplarının, sahip oldukları birçok yapısal avantaj sayesinde, bağı şirketlerine, finansman konusunda da katkılar yaptığı tespit edilmiştir. Yatırımlarını gerçekleştirmek için içsel fonlara bağımlı olmayan bu işletmelerin yatırım davranışı büyük oranda gelecek kar fırsatlarını gösteren $Q$ oranı ile açıklanabilmektedir. Benzer şekilde yabancı ortaklı şirketlerde de içsel fonlara bağımlılık söz konusu olmazken, bu şirketlerin yatırım davranışı da q oranı ile açıklanabilmektedir. Diğer taraftan büyük olmayan işletme gruplarına bağlı şirketler ile herhangi bir gruba bağlı olmayan bağımsız işletmelerin yatırım davranışlarında içsel fonların etkisi istatistiki olarak önemlidir.

Modelde büyük işletme gruplarına bağlı şirketler ile yabancı şirketler için $Q$ değişkeninin istatistiksel olarak anlamlı, nakit akışı değişkeninin ise anlamsız olması, bu grupta yer alan firmaların diğer firmalara göre finans piyasalarından daha etkin yararlandığı ya da bu firmaların sahip oldukları çeşitli avantajlar nedeniyle piyasa aksaklıklarının üstesinden gelebildiği yönünde yorumlanabilir. İlave olarak söz konusu firmaların gelecek kar beklentileri ile ilgili tüm bilgilerin, q oranı tarafından karşılandığı ve bu firmaların yatırımlarını açıklamada kayıp bilgilerin bulunmadığı söylenebilir. 
Büyük olmayan işletme gruplarına bağlı şirketler ile bağımsız şirketlerde ise yatırımlarının belirlenmesinde q oranı, tek başına yetersiz kalmaktadır. Bu nedenle söz konusu firmaların yatırım davranışını açıklamada kullanılacak kayıp bilgilerin içsel fonlar aracılığıyla takip edilmesi gerekir. Bu firmalara ait tahmin sonuçlarından elde edilen anlamlı nakit akışı değişkeninden hareketle, büyük olmayan işletme gruplarına bağlı şirketler ile bağımsız şirketlerin bilgi asimetrisi ve olası vekalet problemleri nedeniyle sermaye piyasalarından yeterince yararlanamadığını ve bu yüzden bu firmalar için finansal kısıtların diğer firmalara göre daha fazla olduğu söylenebilir.

\section{KAYNAKÇA}

Aggarwal, R., Zong, S. (2006), The cash flow-investment relationship: International evidence of limited Access to external finance Journal of Multinational Financial Management 16, 89-104.

Ağca, S., Mozumdar, A. (2008), The Impact of Capital Market Imperfections on Investment-Cash Flow Sensitivity, Journal of Banking and Finance 32, 207-216

Alti, Aydogan, (2003), How sensitive is investment to cash flow when financing is frictionless? Journal of Finance $58,707-722$.

Arellano, M., \& Bond, S. (1991), Some tests of specification for panel data: Monte Carlo evidence and an application to employment equations. The Review of Economic Studies, 58(2), 277-297.

Arellano, M., \& Bover, O. (1995), Another look at the instrumental variable estimation of error-components models. Journal of Econometrics, 68(1), 29-51.

Arslan, Ö., Chrisostomos, F., Ozkan, A. (2006), The role of cash holdings in reducing investment-cash flow sensitivity: Evidence from a financial crisis period in an emerging market Emerging Market Review 7, 320-338

Beck T., Demirgüç-Kunt A., Laeven,L., Maksimovic, V. (2006), The determinants of financing obstacles Journal of International Money and Finance, 25, 932-952

Bhaumik S.K., Das, P.K., Kumbhakar, S.C. (2012), A stochastic frontier approach to modelling financial constraints in firms: An application to India Journal of Banking \& Finance,36, 1311-1319

Bond S., Elston, J., Mairesse, J., Mulkay, B. (2003), Financial factors an investment in Belgium, France, Germany and the UK: a comparison using company panel data Review of Economics and Statistic 13, 153-165

Bond S., Klemm,R., Newton-Smith,A., Syed,R.M., Vlieghe, G. W. (2004), The roles of expected profitability, Tobin's $Q$ and cash flow in econometric models of company investment.

Brainard, W., Tobin, J. (1968), Pitfalls in financial model building, American Economic Review, Vol. 58(2), 99-122.

Chen H., Chen,S. (2011), Investment-cash flow sensitivity cannot be a good measure of financial constraints: Evidence from the time series Journal of Financial Economics 103, 393-410.

Choi, Y.R., Yoshikawa,T., Zahra,S.A., Han, B.H. (2014), Market-oriented institutional change and R\&D investments: Do business Groups enhance advantage? Journal of World Business, 49, 466-475

Chrinko, R., Schaller, J. (1995), Why does liquidity matter in investment equations?, Journal of Money, Credit and Banking, 27, 527- 548.

Clearly S., Povel, P., Raith, M. (2007), The U-shaped investment curve: Theory and evidence Journal of Financal and Quantitative Analaysis 42 (1), 1-40.

Cleary, S. (1999), The relationship between firm investment and financial status Journal of Finance 54, 673-692 
Çetenak, H. (2012), İşletme Grubu İlişsisinin Firma Performansına Etkisi: iMKB'de Bir Uygulama, Yayınlanmamış Doktora Tezi, Çukurova Üniversitesi, Adana

Deloof, M. (1998), Internal capital markets, bank borrowing and finanancing constraints: evidence from Belgian firms Journal of Business Finance and Accounting, 25, 945-968

Egimbaeva, B. (2013), Corporate Investment And Cash Flow Sensitivity: Evidence From Turkey, Yayınlanmamış Yüksek Lisans Tezi, Dokuz Eylül Üniversitesi, İzmir

Erickson, T., Whited, T. M. (2000), Measurement error and the relationship between investment and q. Journal of political economy, 108(5), 1027-1057.

Fazzari S.M., Hubbard,R.G., Peterson, B.C. (1988), Financing constraints and Measurement error and the relationship between investment and q corporate investment Brookings Papers on Economic Activity 1, 141-195

Gallego, F., Loayza, N. (2001), Financial structure in Chile: macroeconomic developments and microeconomic effects. Financial structure and economic growth: A cross-country comparison of banks, markets, and development, 299-346.

Geizici, A. (2009), Financial Liberalization and Financing Constraints: Investment in the Turkish Manufacturing Sector, Econanadolu

Gomes, J.( 2001), Financing Investment American Ecomic Review, 91, 1263-1285

Gorodnichenko, Y., Schaefer, D., Talavera, O. (2009), Financial constraints and continental business groups:Evidence from German Konzerns Research in International Business and Financ, 23, 233-242

Gopalana R., Nanda, V., Seru, A. (2007), Affiliated firms and financial support: Evidence from Indian business groups Journal of Financial Economics 86, 759-795

George, R., Kabir, R., Qian, J. (2011), Investment-cash flow sensitivity and Financing constraints: New evidence from Indian business group firms Journal of Multinational Financial Management 21, 69-88

Hayashi, F (1982), Tobin's average q and marginal q: a neoclassical interpretation', Econometrica, Vol. 50, 213-24

He J., Mao, X., Rui, O.M., Zha, X. (2013), Business Group in China Journal of Corporate Finance, 22, 166-192

Hill, C.W.L. (1988), Internal capital market controls and financal performance in multidivisional firms. The Journal of Industrial Economics. C.37, No:1. 67-83.

Hoshi, T., Kashyap, A., Scharfstein D.(1991), Corporate structure, Liquidity, and Investment: Evidence from Japanese Industrial Groups The Quarterly Journal of Economics, 106 (1), 33-60.

Hubbard, R. G. (1997),Capital-market imperfections and investment (No. w5996), National Bureau of Economic Research.

Hubbard, R.G., Kashyap, A.K., Whited T.M. (1995), Internal Finance and Firm Investment. Journal of Money, Credit and Banking, Volume 27, Issue 3, 683-701.

Islam, S. S., Mozumdar, A. (2007), Financial market development and the importance of internal cash: Evidence from international data. Journal of Banking \& Finance, 31(3), 641-658.

Islam, S. S., Mozumdar, A. (2007), Financial market development and the importance of internal cash: Evidence from international data. Journal of Banking \& Finance, 31(3), 641-658.

Kadapakkam, P.R., Kumar, P. C., Riddick, L.A. (1998), The impact of cash flows and firm size on investment: The international evidence, Journal of Banking and Finance, 22, 293-320.

Kaplan, S.N., Zingales L. (1997), Do investment -cash flow sensitivities provide useful measures of financing constraints Quarterly Journal of Economics 112, 169-215.

Kaplan, S.N., Zingales, L. (2000), Investment -cash flow sensitivities are not valid measures of financing constraints, Quarterly Journal of Economics 115, 707-712. 
Kato, H.K., Loewenstein, U., Tsay W. (2002), Dividend policy, cash flow, and investment in Japan Pacific-Basin Finance Journal 10, $443-473$

Khanna, T. ve Yafeh, Y. (2005), Business groups and risk sharing around the world. Journal of Business, 78, 301340 .

Khanna, T., Palepu, K.(2000), Is Group Affiliation Profitable in Emerging Markets? An Analysis of Diversified Indian Business Groups The Journal of Finance Volume 55, Issue 2, pages 867-891

Knoll, S. (2008), Cross-Business synergies a typology of cross-business synergies and a mid-range theory of continuous growth synergy realization. Doktora tezi, The University of St. Gallen, Almanya

Lensink, R., Van der Molen,R. Gangopadhyay, S.(2003), Business groups, financing constraints and investment: the case of India, The Journal of Development Studies 40 (2), 93-119

Lin C., Ma, Y., Xuan, Y. (2011), Ownership structure and financial constraints: Evidence from a structural estimation, Journal of Financial Economics, 102, 416-431

Lincoln, J. R., Gerlach, M. L. ve Ahmadjian, C. L. (1996), Keiretsu networks and corporate performance in Japan. American Sociological Review, c. 61, 67-88.

Lincoln, J.R. and Michael, L. Gerlach (2004), Japan's Network Economy: Structure, Persistence, and Change. Cambridge University Press.

Mizen, P., Vermeulen, P. (2005), Corporate Investment \& Cash Flow Sensitivity What drives the relationship, European Central Bank Working Paper Series No:485

Modigliani, F., Miller, M. (1958), The cost of capital, corporation finance, and the theory of investment American Economic Review 57, 2061-2092.

Moyen, N.(2004), Investment-Cash Flow Sensitivities: Constrained versus Unconstrained Firms The Journal of Finance, Volume 59, Issue 5, 2061-2092

Myers, S., Majluf, N. (1984), Corporate financing and investment decisions when firms have information that investors do not have Journal of Financial Economics, vol. 13, issue 2, pages 187-221

Pindado, J., Requejo, I., Torre, C. (2011), Family control and investment-cash flow sensitivity: Empirical evidence from the Euro zone Journal of Corporate Finance, Vol.17, issue 5, 1389-1409

Rajan, R., Servaes,H., Zingales, L. (2000), The Cost of Diversity: The Diversification Discount and Inefficient Investment Journal of Finance, vol. 55 issue 1, 35-80

Richardson, S., (2006), Over-investment of free cash flow. Review of Accounting Studies 11, 159- 189.

Sasidharan, S., Lukose, P.J.J., Komera, S. (2015), Financing Constraints and investments in R\&D: Evidence from Indian manufacturing firms The Quarterly Review of Economics and Finance, 55, 28-39

Shin, H.H., and Stulz, R. (1998), Are internal capital markets efficient?, Quarterly Journal of Economics 113, 531553.

Shin, H.H., Park, Y. (1999), Financing constraints and internal capital markets:Evidence from Korean chaebols Journal of Corporate Finance 5, 169-191

Tsai, Y.J., Chen, Y.P., Lin, C.L., Hung J.H. (2014), The effect of bankiing system reform on investment-cash flow sensitivity:Evidence from China Journal of Banking and Finance, 46, 166-176

Williamson, O. E. (2008), Transaction cost economics: the precursors. Journal Compilation Institute of Economic Affairs, c. 28, s. 3, 7-14

Wei, K.C.J., Zhang, Y. (2008), Ownership structure cash flow, and capital investment: Evidence from East Asian economies before financial crisis Journal of Corporate Finance, 14, 118-132 